\title{
Nanocrystalline and monophasic thin films of metal chalcogenide (FeS, ZnS) and oxide (ZnO) by chemical bath deposition (CBD)
}

DOI:

10.1002/pssa.201700008

\section{Document Version}

Accepted author manuscript

Link to publication record in Manchester Research Explorer

Citation for published version (APA):

Akhtar, M. S., Mehmood, R. F., Ahmad, N., Akhtar, M., Revaprasadu, N., \& Malik, M. (2017). Nanocrystalline and monophasic thin films of metal chalcogenide (FeS, ZnS) and oxide (ZnO) by chemical bath deposition (CBD). Physica Status Solidi. A: Applications and Materials Science . https://doi.org/10.1002/pssa.201700008

Published in:

Physica Status Solidi. A: Applications and Materials Science

\section{Citing this paper}

Please note that where the full-text provided on Manchester Research Explorer is the Author Accepted Manuscript or Proof version this may differ from the final Published version. If citing, it is advised that you check and use the publisher's definitive version.

\section{General rights}

Copyright and moral rights for the publications made accessible in the Research Explorer are retained by the authors and/or other copyright owners and it is a condition of accessing publications that users recognise and abide by the legal requirements associated with these rights.

\section{Takedown policy}

If you believe that this document breaches copyright please refer to the University of Manchester's Takedown Procedures [http://man.ac.uk/04Y6Bo] or contact uml.scholarlycommunications@manchester.ac.uk providing relevant details, so we can investigate your claim.

\section{OPEN ACCESS}




\section{Nanocrystalline and monophasic thin films of metal chalcogenide (FeS, $\mathrm{ZnS})$ and oxide ( $\mathrm{ZnO})$ by chemical bath deposition (CBD)}

Muhammad Saeed Akhtar ${ }^{\mathrm{a}^{*}}$, Rana Farhat Mehmood ${ }^{\mathrm{b}}$, Naveed Ahmad ${ }^{\mathrm{a}}$, Masood Akhtar ${ }^{\mathrm{c}, \mathrm{d}}$, Neerish Revaparasadu ${ }^{\mathrm{d}}$, and Mohammad Azad Malik ${ }^{\mathrm{c}, \mathrm{d}^{*}}$

${ }^{a}$ Division of Science and Technology, University of Education, College Road Township, Lahore

${ }^{b}$ University of Education, Lahore, D.G. Khan Campus, Kangan Road, Dera Ghazi Khan, Pakistan

${ }^{\mathrm{c}}$ Schools of Materials, The University of Manchester, Oxford Road, Manchester M13 9PL, UK

${ }^{\mathrm{d}}$ Department of Chemistry, University of Zululand, Private Bag X1001, Kwa-Dlangezwa 3880, South Africa

\section{*Corresponding Authors}

Muhammad Saeed Akhtar

Division of Science and Technology, University of Education, College Road Township, Lahore

E-mail: saeed_khakhi@yahoo.com

Mohammad Azad Malik

Schools of Materials, The University of Manchester, Oxford Road, Manchester M13 9PL, UK

E-mail: $\underline{\text { Azad.malik@ manchester.ac.uk }}$ 


\begin{abstract}
$\mathrm{FeS}, \mathrm{ZnS}$ and $\mathrm{ZnO}$ nanostructured thin films have been deposited by Chemical Bath Deposition (CBD), a simple and cost effective technique. These materials with different morphologies such as nano-flakes, nanoparticles and nanorods for $\mathrm{FeS}, \mathrm{ZnS}$ and $\mathrm{ZnO}$, respectively were deposited onto the glass substrates. The crystallite sizes have been estimated from Scherrer's equation and were found as $14 \mathrm{~nm}$ for nano-flakes of FeS, $9.09 \mathrm{~nm}$ for nanoparticles of $\mathrm{ZnS}$ and $49 \mathrm{~nm}$ for nanorods of $\mathrm{ZnO}$. The average values of the band gaps were found to be $1.97,3.43$ and $3.74 \mathrm{eV}$ for $\mathrm{FeS}, \mathrm{ZnO}$ and $\mathrm{ZnS}$ thin films, respectively. These nanostructured semiconducting materials have wide applications in advanced optoelectronic devices.
\end{abstract}

Keywords: CBD; FeS; ZnS; ZnO; nanostructures; morphology; thin films 


\section{Introduction}

Metal chalcogenides (metal sulfides and oxides) when grown as thin films on various substrate exhibit novel properties which make them viable for potential applications in solar technology, optoelectronic devices and sensors ${ }^{1-11}$. Growth and deposition of cost effective and non-toxic materials by any of the simple chemical technique have gained an enormous research interest owing to their applications in advanced photovoltaic devices ${ }^{12,13}$. Nanostructures of metal chalcogenides especially, FeS, $\mathrm{ZnS}$ and $\mathrm{ZnO}$ are most important among all sulfides and oxides ${ }^{2,}$ 14, 15. There are several physical and chemical techniques reported to date for the deposition of nanostructured thin films on variety of substrates including thermal evaporation ${ }^{16}$, electrodeposition ${ }^{17}$, hydrothermal method ${ }^{18,19}$, sputtering ${ }^{20}$, chemical spray-pyrolysis ${ }^{21,22}$, chemical bath deposition (CBD) ${ }^{2,23-26}$ and aerosol assisted chemical vapor deposition (AACVD) ${ }^{27,}{ }^{28}$. Simple and cost effective nature of the CBD makes it the most attractive method of deposition among the techniques mentioned above. This technique can produce high quality nanostructured thin films and has the benefit of several features such as straightforward processing, large scale deposition and low temperature synthesis in contrast to the difficulties associated with conventional higher temperature and physical methods ${ }^{29}$. Nanostructured thin films of $\mathrm{ZnS}$ and $\mathrm{ZnO}$ have been widely studied but FeS is the least studied phase of iron sulfide. The reports published on CBD of FeS thin films mostly showed amorphous or multi-phases growth of iron sulfide. Kassim et al. in 2010 reported the deposition of iron sulfide thin films by CBD on ITO substrates and observed variation in structural properties as a function of bath temperature ${ }^{23}$. Most recently, authors have published the pioneer work on FeS by CBD and studied the structural and optical properties of thin films. Energy dispersive X-ray spectroscopy revealed the deposition FeS with iron to sulfur ratio close to $1: 1^{24}$. 
$\mathrm{ZnO}$ is a material studied most via CBD regarding deposition of thin films and nanostructures. There are several studies presenting the effects of pertinent factors for achieving the favorable conditions of the synthesis process to achieve uniform growth of $\mathrm{ZnO}$ nanostructures especially, nanorods. The major factors studied to date are; substrates, seed layer thickness, temperature, concentration of precursors and most importantly the role of stabilizing agent ${ }^{30-39}$. Shi and Walker reported recently that stirring produces smoother but less reproducible $\mathrm{ZnO}$ films than sonication-assisted CBD ${ }^{40}$. Rathore et al. presented a growth mechanism of polarity controlled $\mathrm{ZnO}$ nanorods array on a glass/FTO substrate by chemical bath deposition and found that anions of the $\mathrm{Zn}$-salt affect the preferred orientation of growth ${ }^{41}$. Lee et al. reported a novel approach for the synthesis of $\mathrm{ZnO}$ nanotube arrays (ring-like structures) using the polymer-based seeding solution through the Marangoni mechanism, guiding the growth of $\mathrm{ZnO}$ nanotubes with aqueous chemical bath deposition ${ }^{42}$.

Deposition of uniform $\mathrm{ZnS}$ thin films by CBD is bit tricky compared to the deposition of $\mathrm{CdS}$ and $\mathrm{ZnO}$ by the same technique owing to the chemistry of reactions taking place to produce $\mathrm{ZnS}$ thin films by CBD. The role of complexing agent along with $\mathrm{pH}$ of the solution has crucial importance in deposition of oxygen free $\mathrm{ZnS}$ thin films by $\mathrm{CBD}^{43-46}$. Optimized conditions for the growth of nanocrystalline $\mathrm{ZnS}$ thin films by $\mathrm{CBD}$ have been reported recently by the authors 47 . Herein, we report a simple, cost effective and reproducible method to deposit monophasic and nanocrystalline thin films of $\mathrm{FeS}, \mathrm{ZnS}$ and $\mathrm{ZnO}$ on glass substrates without seed layers. It is believed that, without seed layer, the growth of films or nano-structures may be slower or missoriented due to lattice-mismatch, adhesion, stress etc. ${ }^{48,49}$. Large lattice mismatch between glass substrate and deposited nanostructures obstruct the oriented growth of nanostructures. However, 
in the current research work focus on the optimization of synthesis parameters instead of using seed layers grow nanostructures especially vertically aligned $\mathrm{ZnO}$ nanorods. 


\section{2. .Experimental}

\subsection{Chemicals}

All reagents, iron chloride tetra-hydrate, zinc chloride, thioacetamide, hexamethylenetetramine and urea were purchased from Sigma-Aldrich and used without further purification. De-ionized water was used as solvent in all experiments.

\subsection{Instruments}

Thermostat bath connected with jacketed beaker was used for deposition of thin films on glass substrates. Bruker D8 advance Diffractometer with $\mathrm{Cu}-\mathrm{K} \alpha$ radiation was used for X-ray powder diffraction measurements. SEM analysis was carried out using Hitachi S3400N microscope. TEM and SAED images were collected from a Tecnai 20 F30 transmission electron microscope with accelerating voltage of $200 \mathrm{kV}$. The calculations of band gaps were performed after acquiring data from an Agilent HP $8453 \mathrm{UV}$-Vis spectrophotometer. Photoluminescence data were obtained on a Fluorolog 22, HORIBA PL using excitation wavelength of $340 \mathrm{~nm}$.

\subsection{Substrate preparation}

Diamond scriber was used to cut glass slides into substrates with dimensions $1 \times 3 \mathrm{~cm}^{2}$. Glass substrates were degreased with ethanol and then cleaned ultrasonically by acetone, 2-propanol and de-ionized water for ten minutes each, respectively. Two glass substrates were joined together and hanged vertically into the solution bath with help of Teflon substrate holder in order to avoid deposition of thin films on both sides of the substrate.

\subsection{Synthesis of FeS thin films}

The FeS thin films were deposited from chemical bath having solutions of thioacetamide, urea and iron trichloride as reported earlier ${ }^{24}$. The solutions of iron trichloride $(0.15 \mathrm{M})$, urea $(1 \mathrm{M})$ 
and thioacetamide with molar concentrations of $0.15,1$ and $2 \mathrm{M}$ were prepared separately in deionized water under stirring for half an hour to get $30 \mathrm{~mL}$ for each precursor solution. Urea solution was added dropwise to the iron trichloride solution followed by the addition of thioacetamide solution under stirring. After two hours of stirring, a transparent solution was achieved. To adjust the $\mathrm{pH}$ of solution, $0.5 \mathrm{M}$ hydrochloric acid was prepared and added dropwise to the solution till the $\mathrm{pH}$ reached to 2.5 . The reaction mixture was kept at $85^{\circ} \mathrm{C}$ in thermostat bath. Color of the reaction mixture starts changing from transparent to blackish and after 30 minutes of reaction turns dark black (Figure 1). At this stage, glass substrates were immersed vertically into the bath and removed after 3 hours. Deposited thin films were washed with de-ionized water immediately after removing from the bath to remove slackly adherent deposits and then dried at room temperature. No post deposition heat treatment was carried out before characterizations.

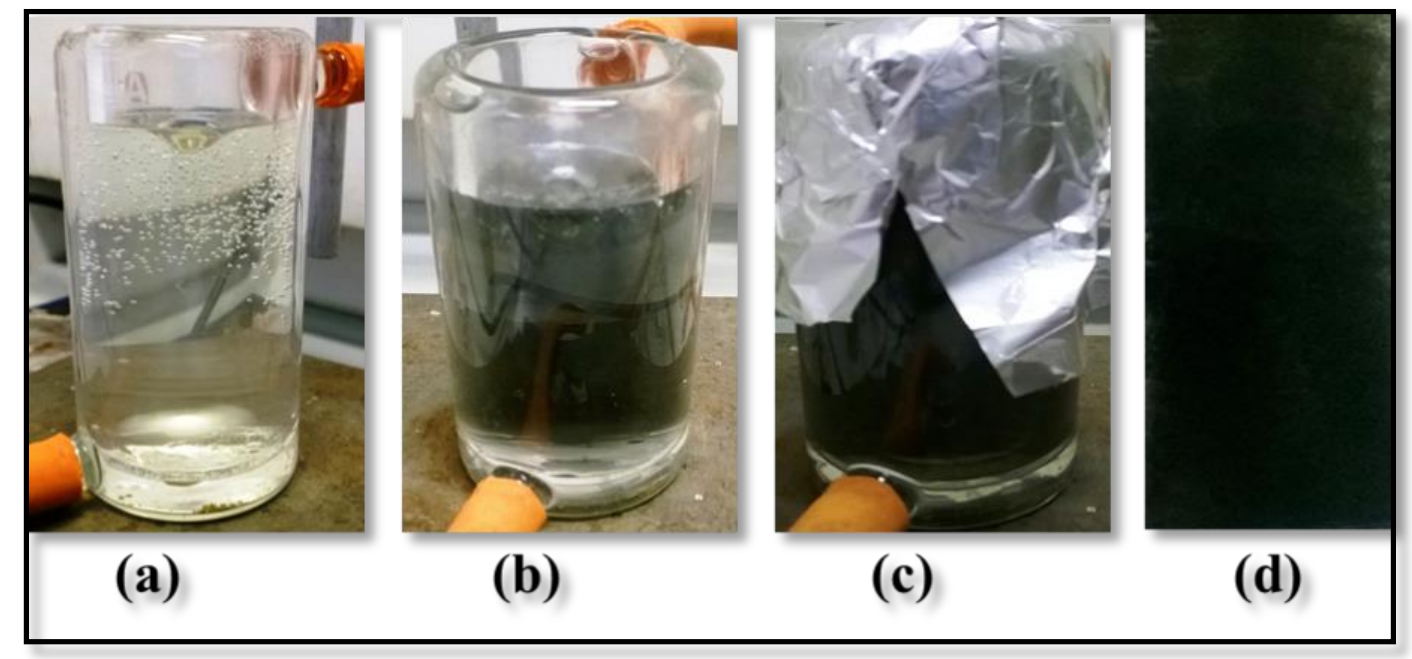

Figure 1: Transformation of the color of reaction mixture from (a) transparent to (c) dark black and (d) as-deposited thin film of FeS on glass substrate

\subsection{Synthesis of $\mathrm{ZnS}$ thin films}


For growth of $\mathrm{ZnS}$ thin films, solutions $(30 \mathrm{~mL}$ each) of urea, thioacetamide and zinc chloride were prepared in de-ionized water with concentrations of $0.15,1$ and $5 \mathrm{M}$, respectively ${ }^{2}$. Solution of urea was added dropwise to zinc chloride solution followed by addition of thioacetamide solution under continuous stirring at room temperature. The $\mathrm{pH}$ of reaction mixture was fixed to 4.0 by adding $0.5 \mathrm{M} \mathrm{HCl}$ drop wise. The reaction mixture was then transferred to the chemical bath and maintained at $80^{\circ} \mathrm{C}$. Pre-cleaned glass substrates were held vertical by substrate holder into the reaction beaker just after five minutes of turbidity and removed after three hours (Figure 2). As-deposited thin films were washed with de-ionized water and dried at ambient atmosphere before characterization.

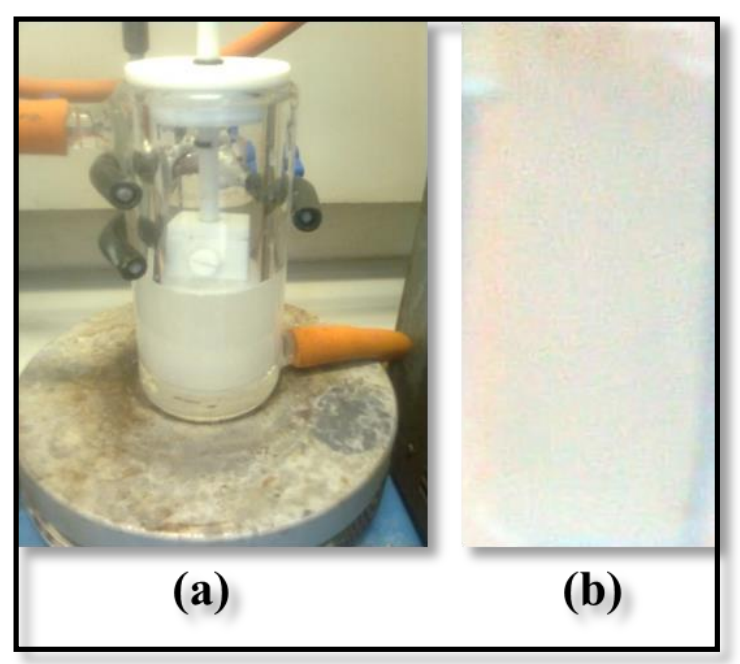

Figure 2: (a) Reaction mixture for deposition of $\mathrm{ZnS}$ (b) as-deposited thin film of $\mathrm{ZnS}$ on glass substrate

\subsection{Synthesis of $\mathrm{ZnO}$ thin films}

The $\mathrm{ZnO}$ thin films were grown on the glass substrates from chemical bath having equimolar solutions of zinc chloride and hexamethylenetetramine. The solutions of zinc chloride and hexamethylenetetramine, $50 \mathrm{~mL}$ each prepared separately in de-ionized water. These solutions were then mixed gradually to have the bath solution of $100 \mathrm{~mL}$. The solution was maintained at a 
temperature of $95^{\circ} \mathrm{C}$ in thermostat bath (Figure 3). Ultrasonically cleaned glass substrates were held vertically into the bath and withdrawn after 3 hours followed by washing with de-ionized water. The deposited thin films after removal from the bath appeared white in color which were then dried at room temperature before further characterization.

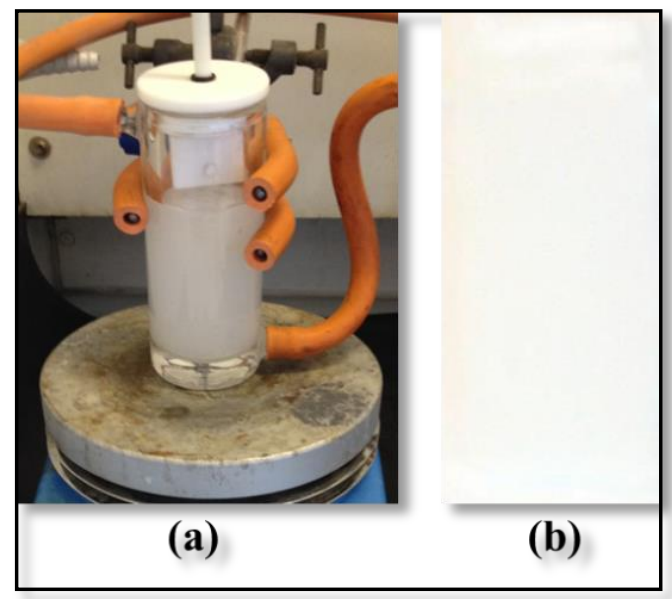

Figure 3: (a) Reaction mixture for deposition of $\mathrm{ZnO}$ (b) as-deposited thin film of $\mathrm{ZnO}$ on glass substrate

\section{Results and Discussion}

\subsection{Structural studies}

Figure 4 shows the XRD pattern of as-deposited FeS thin films is in good agreement with that of tetragonal phase of FeS (ICDD pattern \# 01-086-0389). Black vertical lines in Figure 4 represent the standard pattern of FeS. The existence of an intense and distinct diffraction peak divulges the well crystallized and monophasic growth of FeS preferentially grown along (001) plane ${ }^{24}$. Additional peaks are not observed indicating that no impurity phases are formed during the synthesis of FeS thin films. Scherrer's equation was used to estimate the crystallite size and found to be $14 \mathrm{~nm}$. 


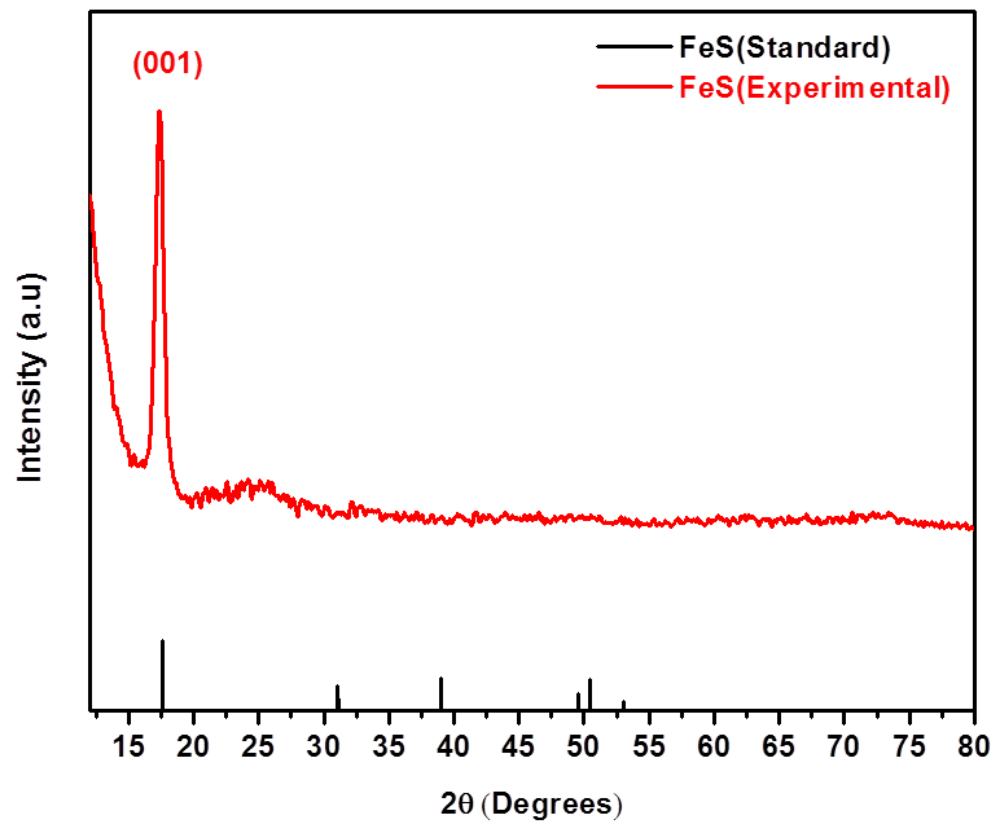

Figure 4: XRD pattern of FeS thin film.

Figure 5 reveals the XRD pattern of $\mathrm{ZnS}$ thin films. The broad diffraction peaks correspond to the lattice planes of cubic phase i.e. (111), (220) and (311) well accorded to the standard data (ICSD \# 01-080-0020). No diffraction peaks corresponding to hexagonal phase of $\mathrm{ZnS}$ were detected. The observed XRD pattern for $\mathrm{ZnS}$ is in close agreement with the observations reported earlier ${ }^{50,51}$. 


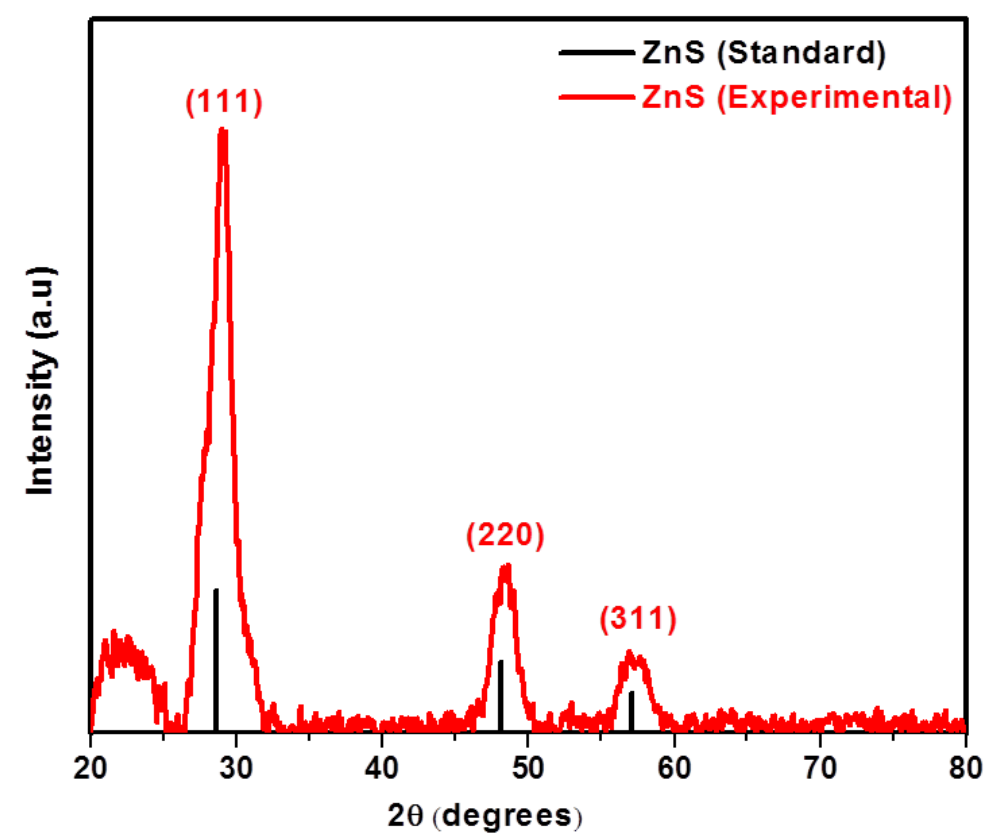

Figure 5: XRD pattern of $\mathrm{ZnS}$ thin film.

Broad diffractions peaks represent the nano-crystallinity of the films ${ }^{47}$ rather than deposition of amorphous material as reported previously by several authors ${ }^{52-54}$. The average crystallite size in case of $\mathrm{ZnS}$ deposition was $9.09 \mathrm{~nm}$ and is close to that observed by Man and Lee ${ }^{50}$.

$\mathrm{XRD}$ pattern of $\mathrm{ZnO}$ thin films reveal the deposition of polycrystalline material exhibiting hexagonal wurtzite structure. The obtained diffraction peaks (Figure 6) correspond to (002) and (004) lattice planes which are well matched with reported data (JCPDS card \# 00-001-1136). Intensity of (002) peak indicates the growth of $\mathrm{ZnO}$ along preferred orientation of c-axis ${ }^{30}$. It is important to mention here that $\mathrm{ZnO}$ thin films are grown onto the bare glass substrates without any seed layer of $\mathrm{ZnO}$ nanoparticles. The average crystallite size for $\mathrm{ZnO}$ nanorods estimated through Scherrer relation is $49 \mathrm{~nm}$. 


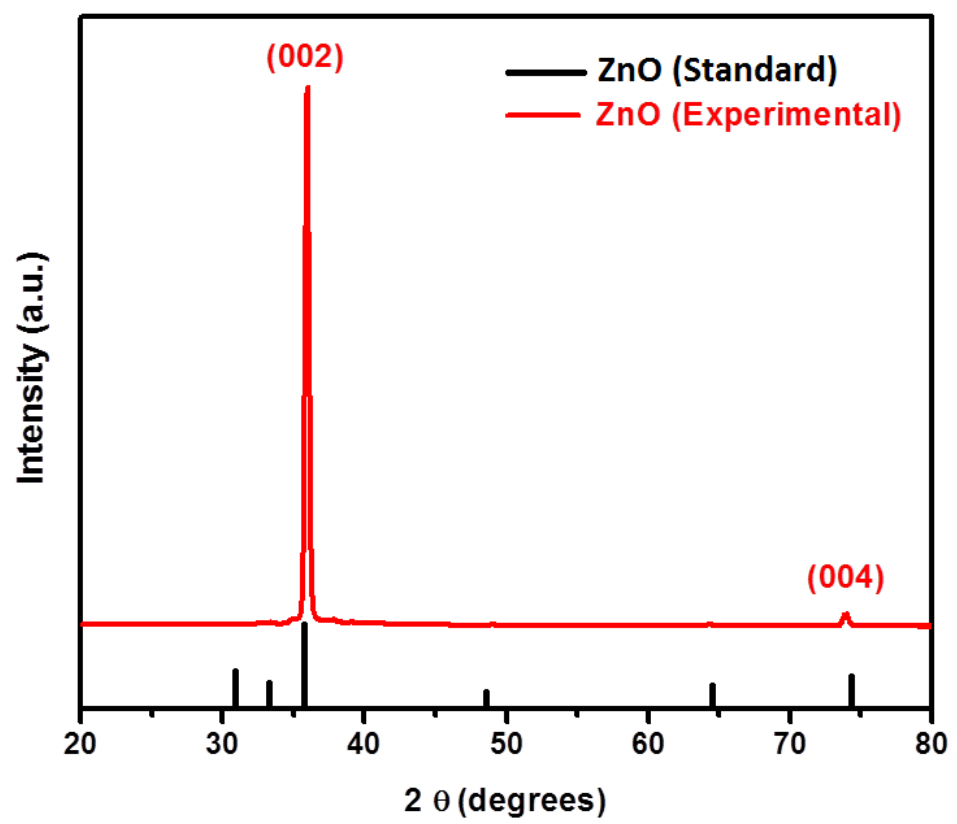

Figure 6: XRD pattern of $\mathrm{ZnO}$ thin film.

The preferred orientation of $\mathrm{ZnO}$ thin films was confirmed by Harris analysis using the formula of texture coefficient ${ }^{55} ; P(h k l)=\frac{I(h k l)}{I \circ(h k l)}\left[\frac{1}{n} \sum_{i=1}^{n} \frac{I(h k l)}{I \circ(h k l)}\right]^{-1}$, where I is the observed relative intensity with respect to the most intense diffraction peak, $I_{0}$ is the standard relative intensity for (hkl) plane obtained from JCPDS card \# 00-001-1136 and $\mathrm{n}$ is the number of peaks in the diffraction pattern. For preferentially oriented sample the $\mathrm{P}(\mathrm{hkl})$ value should be greater than 1 and in the case of $\mathrm{ZnO}$ thin films, $\mathrm{P}(002)$ is greater than ' 1 ' showing the preferred orientation of deposited thin films.

The dislocation density $(\delta)$, defined as the length of dislocation lines per unit volume was estimated using the equation ${ }^{56} ; \delta=\frac{1}{\mathrm{D}^{2}}$ and obtained as $0.0051,0.0625$ and $0.0028 \mathrm{~nm}^{-2}$ for $\mathrm{FeS}, \mathrm{ZnS}$ and $\mathrm{ZnO}$ thin films, respectively. Where ' $\mathrm{D}$ ' is crystallite size calculated from Scherrer's equation. The low values of dislocation line density indicating progressive annihilation of linear defects that would confirm the compatibility of thin films with substrates 
and ultimately resulted in enhanced optical and mechanical properties of deposited thin films. Thin films with minimum dislocation densities or virtually dislocation-free can have applications in devices.

\subsection{Morphology of thin films}

The SEM images of $\mathrm{FeS}, \mathrm{ZnS}$ and $\mathrm{ZnO}$ thin films at same magnification are shown in Figure 7 and reveal growth of nanostructures with different morphologies. In case of FeS, anisotropic growth of nano-flakes occurred with size $\leq 200 \mathrm{~nm}$ resulted from nucleation of crystallites on the surface of substrate. The SEM micrograph for $\mathrm{ZnS}$ thin film shown in Figure 7 indicates the growth of nanoparticles which are distributed uniformly onto the substrate surface. These nanoparticles are in the form of spherical agglomerates ${ }^{57}$ with an average size of $100 \mathrm{~nm}$. These agglomerated grains are formed by combination of very small crystallites as estimated by XRD analysis 58,59 .

The nanorods of $\mathrm{ZnO}$ (Figure 7) were grown on glass substrates with a hexagonal prism shape facets ${ }^{60}$. Note that the nanorods are dense enough even without use of any seed layer and grown along the c-axis (002) orientation. A well aligned vertical growth of these nanorods can be possible by using seed layer of $\mathrm{ZnO}$ nanoparticles before chemical bath deposition as reported in

literature ${ }^{30,61,62}$. However, the observed morphology of $\mathrm{ZnO}$ nanorods grown on glass substrates without seed layer is in close agreement with that observed earlier with seed layer ${ }^{60}$. 

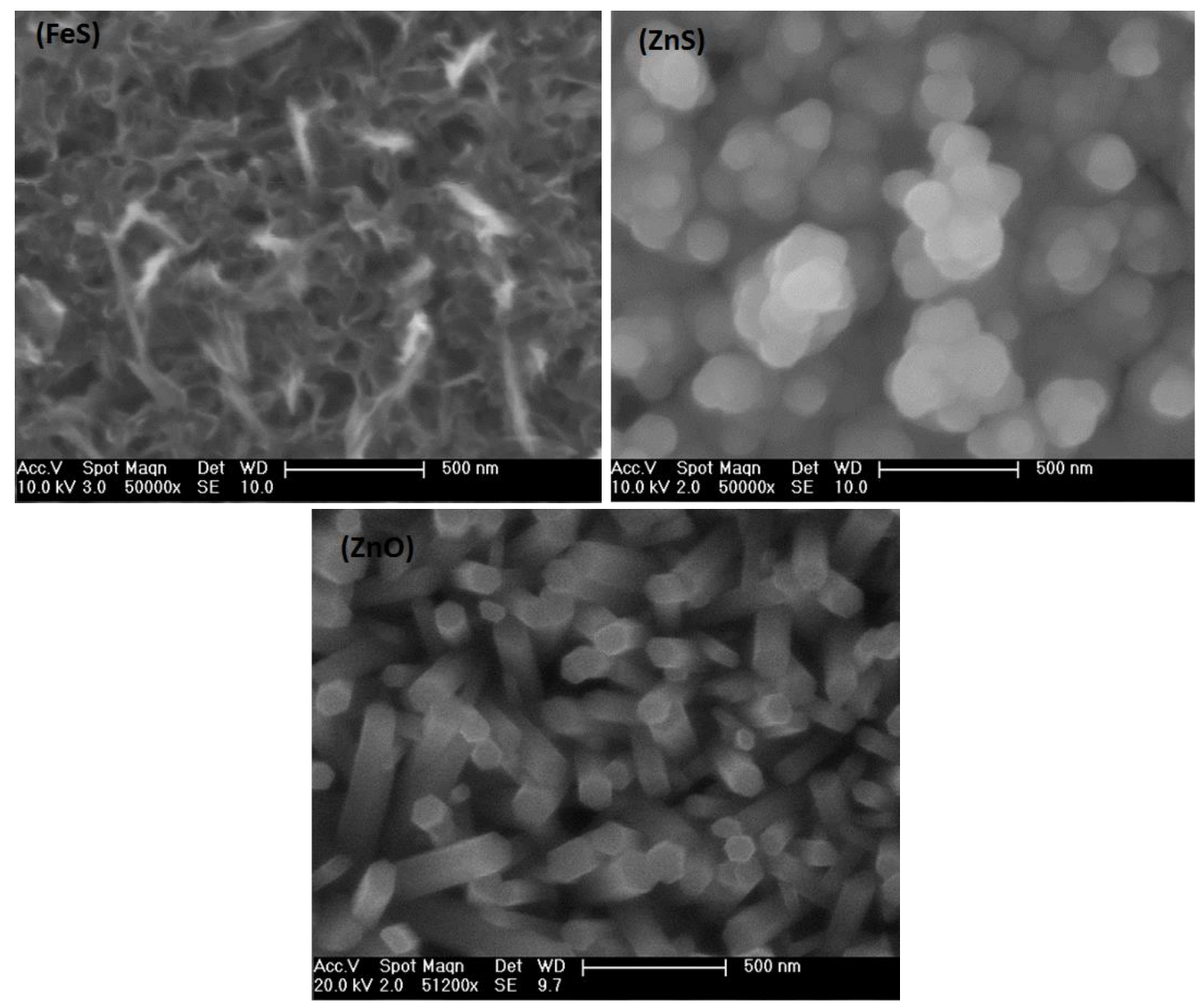

Figure 7: SEM micrographs of FeS, $\mathrm{ZnS}$ and $\mathrm{ZnO}$ thin films

Further microstructural study was carried out by typical TEM and HR-TEM. Thin films were scratched from the glass substrate and were dispersed in ethanol followed by casting and drying on copper grids. Figure 8 illustrate that FeS nanocrystals are anisotropic while ZnS nanocrystals are in the form of spherical clusters made up of small nanoparticles. Inset image of selected area electron diffraction pattern for $\mathrm{ZnS}$ depict the appearance of diffraction rings. The observed diffraction rings correspond to electron diffraction from three planes as observed in XRD of $\mathrm{ZnS}$ thin films. In case of $\mathrm{ZnO}$, TEM reveals the growth of nanorods with average length and diameter as 350 and $100 \mathrm{~nm}$, respectively. Inset image (HRTEM) shows the d-spacing of 0.26 
$\mathrm{nm}$ correspond to the most intense XRD peak i.e. (002) as observed in XRD analysis of ZnO thin films confirming the growth along c-axis.
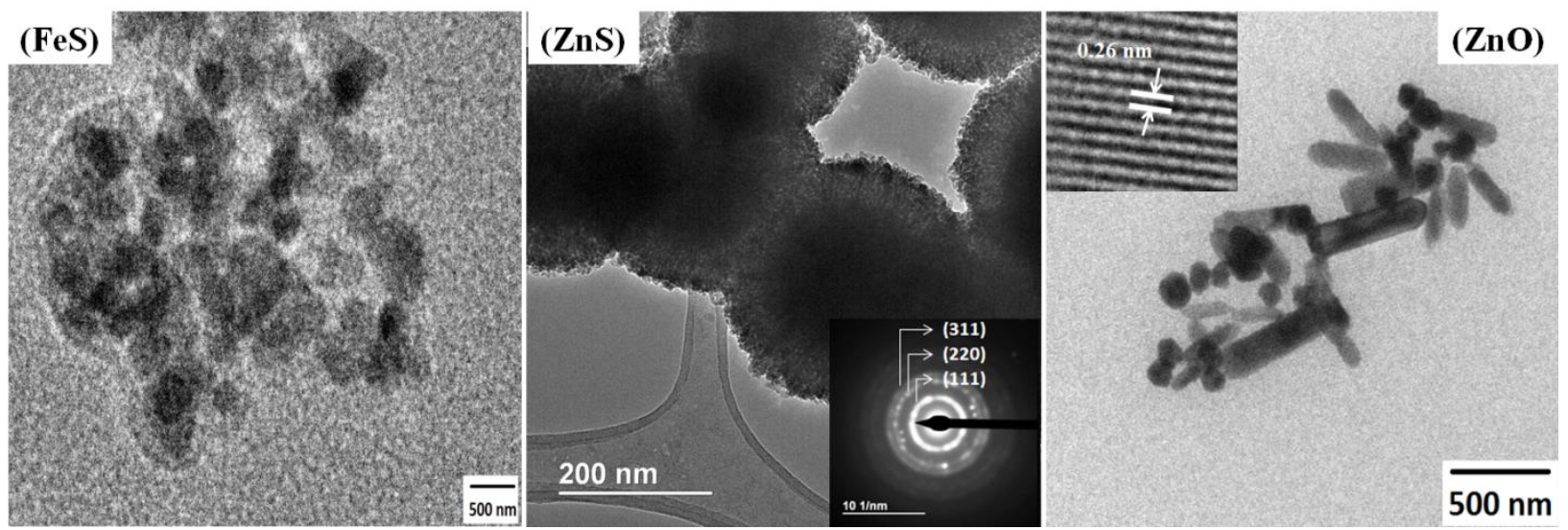

Figure 8: TEM images of $\mathrm{FeS}, \mathrm{ZnS}$ and $\mathrm{ZnO}$

\subsection{Optical studies}

To evaluate the optical properties of deposited thin films, optical band gaps were determined. The band gap calculation was performed simply by inferring the linear part of the $(\alpha h v)^{2} V s$ hv curves to the energy axis, when $(\alpha h v)^{2}=0$. The band gaps were found to be $1.97,3.43$ and 3.74 $\mathrm{eV}$ for $\mathrm{FeS}^{63}, \mathrm{ZnO}^{64}$ and $\mathrm{ZnS}{ }^{58}$ thin films, respectively (Figure 9). The observed values of band gap are found to be slightly higher than those reported earlier for these materials ${ }^{24,59}$ which might be attributed more to the increment in surface area of deposited nanocrystals depending on their geometrical shape and less to the quantum confinement phenomenon. The variation of $(\alpha h v)^{2}$ with photon energy hv (Figure 9) depicts a direct type of transition in all materials.

Photoluminescence of deposited metal chalcogenide thin films under excitation wavelength of $340 \mathrm{~nm}$ was observed at room temperature. Emission spectra are shown in Figure 10. The broad emission peak observed at $641 \mathrm{~nm}$ for FeS can be assigned as its characteristic peak confirming the monophasic nature of deposited material. 


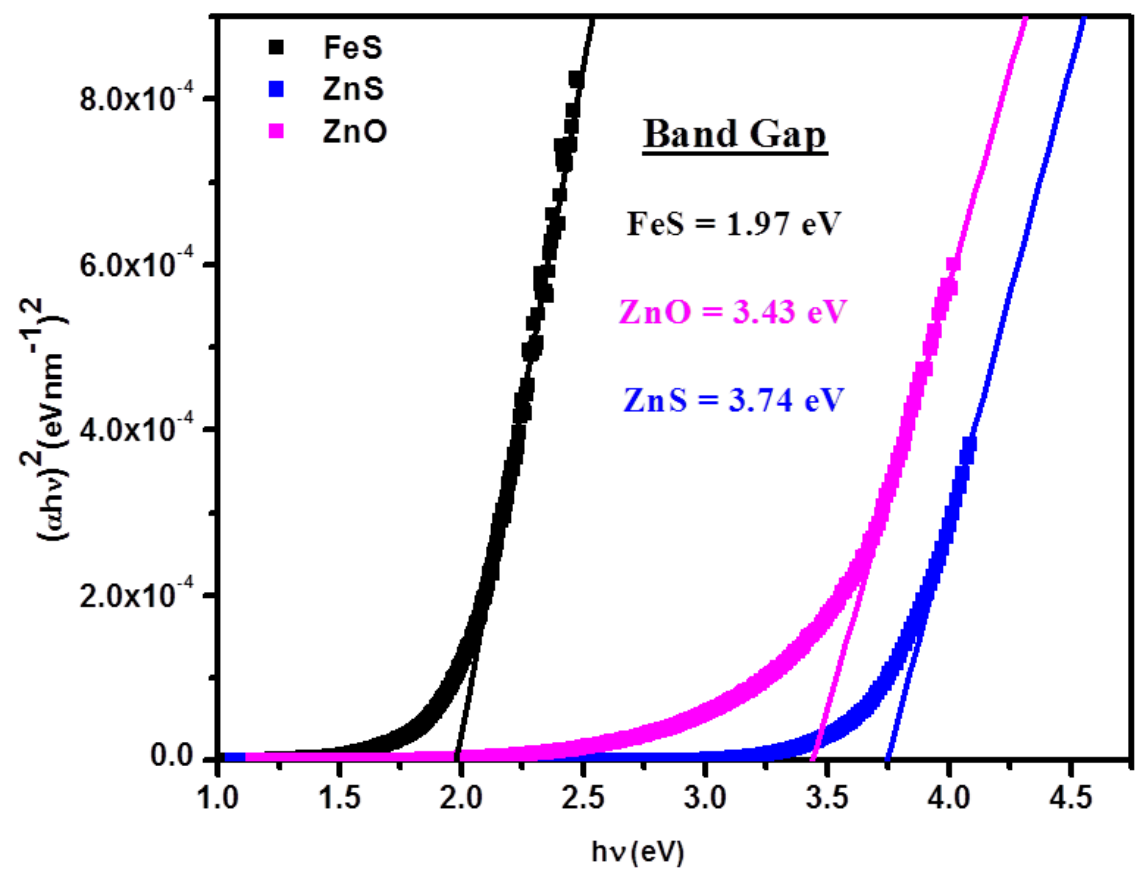

Figure 9: Bandgaps of $\mathrm{FeS}, \mathrm{ZnS}$ and $\mathrm{ZnO}$ thin films deposited on glass substrate by $\mathrm{CBD}$

The photoluminescence spectra observed at room temperature for $\mathrm{ZnS}$ and $\mathrm{ZnO}$ thin films show two emission bands in each case. For ZnS thin films, emissions bands at 397 and $498 \mathrm{~nm}$ were observed and for $\mathrm{ZnO}$ thin films, emissions bands at 389 and $504 \mathrm{~nm}$ were observed. The emissions at 397 and $389 \mathrm{~nm}$ are attributed to the well-known near band edge (NBE) emission of the wide band gap of semiconductors and mainly came from the exciton recombination of the photo-generated holes in the valence band and the electrons in the conduction band through an exciton-exciton collision process when materials are chemically synthesized at nano scale ${ }^{65-68}$. The emissions at 498 and $504 \mathrm{~nm}$ are attributed to the zinc interstitial and oxygen vacancy related defect levels which act as luminescence centers for deposited thin films ${ }^{69,}{ }^{70}$. These luminescence centers enhance the radiative recombination processes and substantially increase PL intensity of green emission. The observed optical properties revealed that the deposited nanocrystalline, monophasic and pure thin films can have applications in advanced optoelectronic devices. Both the surface recombination and structural parameters have great 
impact on designing of thin film solar cells in order to obtain the maximum conversion efficiency 71.

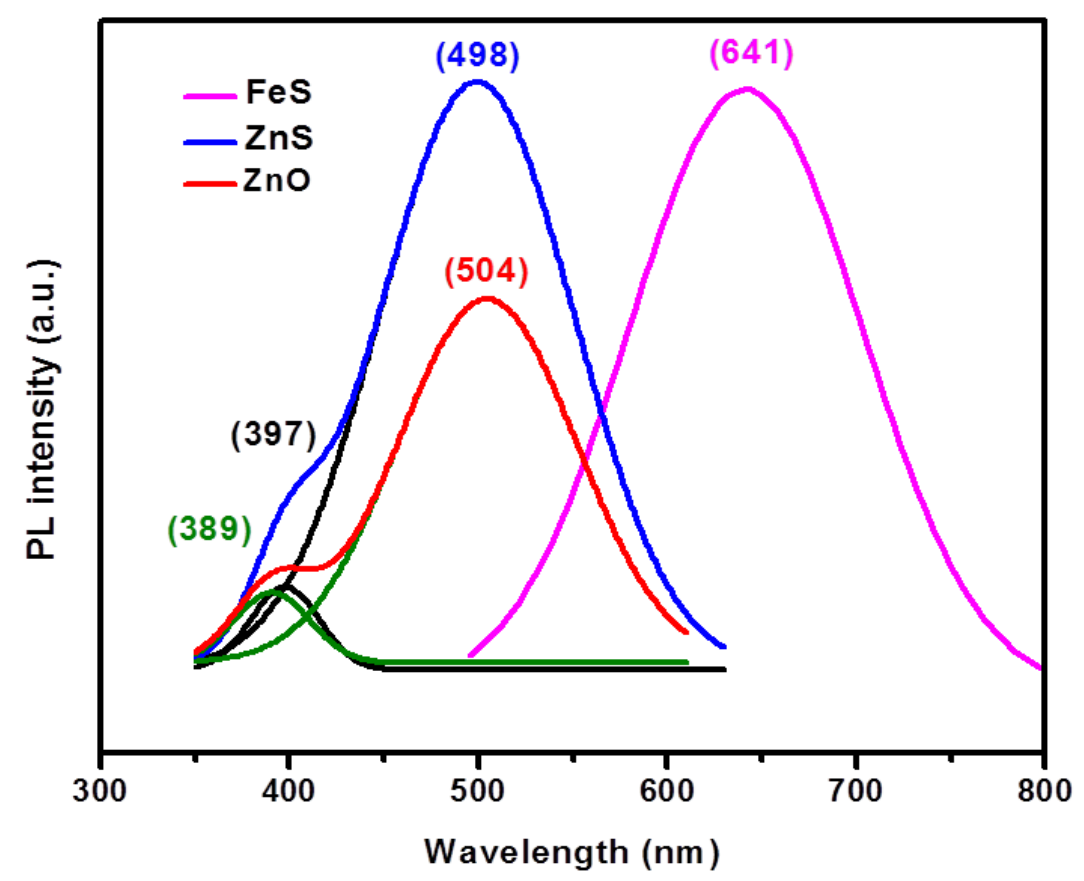

Figure 10: PL spectra of FeS, $\mathrm{ZnS}$ and $\mathrm{ZnO}$ thin films deposited on glass substrate by CBD.

\section{Conclusions}

In summary, growth of monophasic and nanocrystalline thin films $\mathrm{FeS}, \mathrm{ZnS}$ and $\mathrm{ZnO}$ has been accomplished by $\mathrm{CBD}$ on glass substrates. The XRD revealed that the deposited thin films exhibit tetragonal (mackinawite) phase for FeS, cubic (zinc blende) phase for $\mathrm{ZnS}$ and hexagonal (wurtzite) phase for $\mathrm{ZnO}$, without evidence of other phases of these materials. The SEM images show the growth of nano-flakes of FeS, nanoparticles of $\mathrm{ZnS}$ and nanorods of $\mathrm{ZnO}$. The deposited films show high crystallinity and good adhesion. Optical studies revealed that nanostructured thin films exhibit direct band transitions with enhanced photoluminescence and have potential applications in advanced optoelectronic devices. 


\section{Acknowledgement}

One of the authors (M. Saeed Akhtar) would like to acknowledge the Higher Education Commission (HEC) of Pakistan for providing financial support as start-up research grant under IPFP (Grant no. 21-867/SRGP/R\&D/HEC/2016)

\section{Conflicts of Interest}

The authors would like to declare no conflict of interest. 


\section{References}

1. N. Revaprasadu, M. A. Malik, P. O'Brien and G. Wakefield, Journal of materials research, 1999, 14, 3237-3240.

2. M. S. Akhtar, M. A. Malik, S. Riaz and S. Naseem, Materials Science in Semiconductor Processing, 2015, 30, 292-297.

3. M. S. Akhtar, M. A. Malik, S. Riaz and S. Naseem, Materials Chemistry and Physics, 2015, 160, 440-446.

4. A. A. Memon, M. Afzaal, M. A. Malik, C. Q. Nguyen, P. O'Brien and J. Raftery, Dalton Transactions, 2006, 4499-4505.

5. A. L. Abdelhady, M. A. Malik and P. O'Brien, Journal of Inorganic and Organometallic Polymers and Materials, 2014, 24, 226-240.

6. L. D. Nyamen, A. A. Nejo, V. S. Pullabhotla, P. T. Ndifon, M. A. Malik, J. Akhtar, P. O'Brien and N. Revaprasadu, Polyhedron, 2014, 67, 129-135.

7. M. Akhtar, M. A. Malik, F. Tuna and P. O'Brien, Journal of Materials Chemistry A, 2013, 1, 87668774.

8. A. L. Abdelhady, M. A. Malik, P. O'Brien and F. Tuna, The Journal of Physical Chemistry C, 2012, 116, 2253-2259.

9. M. Akhtar, J. Akhter, M. A. Malik, P. O'Brien, F. Tuna, J. Raftery and M. Helliwell, Journal of Materials Chemistry, 2011, 21, 9737-9745.

10. K. Ramasamy, M. A. Malik, M. Helliwell, F. Tuna and P. O’Brien, Inorganic chemistry, 2010, 49, 8495-8503.

11. M. AzadáMalik, Journal of Materials Chemistry, 1994, 4, 1249-1253.

12. T. Bai, Y. H. Xie, J. Hu, C. Y. Zhang and J. D. Wang, J Alloy Compd, 2015, 644, 350-353.

13. S. A. Vanalakar, S. S. Mali, M. P. Suryawanshi, N. L. Tarwal, P. R. Jadhav, G. L. Agawane, K. V. Gurav, A. S. Kamble, S. W. Shin, A. V. Moholkar, J. Y. Kim, J. H. Kim and P. S. Patil, Opt Mater, 2014, 37, 766-772.

14. W. Y. Chang, T. H. Fang and J. H. Tsai, J Low Temp Phys, 2015, 178, 174-187.

15. S. R. T. Djiokap, Z. N. Urgessa, C. M. Mbulanga, A. Venter and J. R. Botha, Physica B, 2016, 480, 68-71.

16. H. V. Chung, P. T. Huy, T. T. An, N. T. M. Thuy and N. D. Chien, J Korean Phys Soc, 2008, 52, 15621565.

17. J. R. S. Brownson and C. Levy-Clement, Phys Status Solidi B, 2008, 245, 1785-1791.

18. J. Cao, L. Fan, J. H. Yang, Y. S. Yan, M. B. Wei, L. L. Yang, B. Feng, D. L. Han, B. J. Wang and H. Fu, Superlattice Microst, 2013, 57, 58-65.

19. Y. Z. Zheng, H. Y. Ding, Y. Liu, X. Tao, G. Z. Cao and J. F. Chen, Electrochim Acta, 2014, 145, 116122.

20. A. F. Khan, M. Mehmood, A. M. Rana and M. T. Bhatti, App/ Surf Sci, 2009, 255, 8562-8565.

21. P. O. Offor, B. A. Okorie, B. A. Ezekoye, V. A. Ezekoye and J. I. Ezema, Journal of Ovonic Research, 2015, 11, 73-77.

22. N. Bouguila, D. Bchiri, M. Kraini, A. Timoumi, I. Halidou, K. Khirouni and S. Alaya, Journal of Materials Science-Materials in Electronics, 2015, 26, 9845-9852.

23. A. Kassim, H. S. Min, A. Sharif and S. Nagalingam, Stud U Babes-Bol Che, 2010, 55, 5-11.

24. M. S. Akhtar, A. Alenad and M. A. Malik, Materials Science in Semiconductor Processing, 2015, 32, 1-5.

25. S. Guillemin, E. Appert, H. Roussel, B. Doisneau, R. Parize, T. Boudou, G. Bremond and V. Consonni, J Phys Chem C, 2015, 119, 21694-21703.

26. P. O'Brien, E. Hill, M. Malik and M. Toohey, Materials Letters, 2007, 61, 284-287. 
27. M. Afzaal, D. Crouch, M. A. Malik, M. Motevalli, P. O'Brien and J.-H. Park, Journal of Materials Chemistry, 2003, 13, 639-640.

28. K. Ramasamy, V. L. Kuznetsov, K. Gopal, M. A. Malik, J. Raftery, P. P. Edwards and P. O’Brien, Chemistry of Materials, 2013, 25, 266-276.

29. S. Maiti, S. Pal and K. K. Chattopadhyay, Crystengcomm, 2015, 17, 9264-9295.

30. M. Poornajar, P. Marashi, D. H. Fatmehsari and M. K. Esfahani, Ceram Int, 2016, 42, 173-184.

31. W. L. Feng, B. C. Wang, P. Huang, X. D. Wang, J. Yu and C. W. Wang, Mat Sci Semicon Proc, 2016, 41, 462-469.

32. W. Zhang, P. Wang, X. N. Fei, Y. Xiu and G. Z. Jia, Int J Electrochem Sc, 2015, 10, 4688-4695.

33. L. S. Zhang, K. Jin, S. Z. Li, L. Z. Wang, Y. Zhang and X. F. Li, J Electron Mater, 2015, 44, 244-251.

34. Z. L. Yuan, J Electron Mater, 2015, 44, 1187-1191.

35. F. Waltz, H. C. Schwarz, A. M. Schneider, S. Eiden and P. Behrens, Beilstein J Nanotech, 2015, 6, 799-808.

36. S. Valanarasu, A. Kathalingam, J. K. Rhee, R. Chandramohan, T. A. Vijayan and M. Karunakaran, J Nanosci Nanotechno, 2015, 15, 1416-1420.

37. T. Terasako, N. A. Hambali, N. A. Jayah, T. Wakisaka, A. M. Hashim and M. Yagi, Thin Solid Films, 2015, 596, 201-208.

38. R. Shabannia, Prog Nat Sci-Mater, 2015, 25, 95-100.

39. K. O. Iwu, V. Strano, A. Di Mauro, G. Impellizzeri and S. Mirabella, Cryst Growth Des, 2015, 15, 4206-4212.

40. Z. W. Shi and A. V. Walker, Langmuir, 2015, 31, 1421-1428.

41. N. Rathore, D. V. S. Rao and S. K. Sarkar, Rsc Adv, 2015, 5, 28251-28257.

42. W. C. Lee, Y. X. Fang, R. Kler, G. E. Canciani, T. C. Draper, Z. T. Y. Al-Abdullah, S. M. Alfadul, C. C. Perry, H. Y. He and Q. Chen, Mater Chem Phys, 2015, 149, 12-16.

43. H. J. Zhu, X. M. Wang and X. Y. Gao, Journal of the Korean Physical Society, 2015, 67, 366-370.

44. E. Yucel and Y. Yucel, Journal of Materials Science-Materials in Electronics, 2015, 26, 196-203.

45. B. Opasanont and J. B. Baxter, Crystal Growth \& Design, 2015, 15, 4893-4900.

46. K. J. Meitzner, B. M. Tillotson, A. T. Siedschlag, F. G. Moore, S. D. Kevan and G. L. Richmond, Thin Solid Films, 2015, 593, 131-136.

47. M. S. Akhtar, M. A. Malik, S. Riaz, S. Naseem and P. O'Brien, Materials Science in Semiconductor Processing, 2015, 30, 292-297.

48. E. Pourshaban, H. Abdizadeh and M. R. Golobostanfard, Procedia Materials Science, 2015, 11, 352-358.

49. R. Shabannia and H. Abu-Hassan, Materials Letters, 2013, 90, 156-158.

50. M. T. Man and H. S. Lee, Current Applied Physics, 2015, 15, 761-764.

51. F. P. Yu, S. L. Ou, P. C. Yao, B. R. Wu and D. S. Wuu, J Nanomater, 2014.

52. C. A. Rodriguez, M. G. Sandoval-Paz, G. Cabello, M. Flores, H. Fernandez and C. Carrasco, Materials Research Bulletin, 2014, 60, 313-321.

53. P. A. Luque, A. Castro-Beltran, A. R. Vilchis-Nestor, M. A. Quevedo-Lopez and A. Olivas, Materials Letters, 2015, 140, 148-150.

54. L. M. Zhou, N. Tang and S. M. Wu, Surface \& Coatings Technology, 2013, 228, S146-S149.

55. C. Barrett and T. Massalski, Oxford, 1980.

56. Y. S. Jung, W. K. Choi, O. V. Kononenko and G. N. Panin, J Appl Phys, 2006, 99, 013502.

57. R. K. Choubey, S. Kumar and C. W. Lan, Advances in Natural Sciences-Nanoscience and Nanotechnology, 2014, 5.

58. A. X. Wei, J. Liu, M. X. Zhuang and Y. Zhao, Materials Science in Semiconductor Processing, 2013, 16, 1478-1484.

59. P. A. Luque, M. A. Quevedo-Lopez and A. Olivas, Materials Letters, 2013, 106, 49-51. 
60. K. Nouneh, T. Ajjammouri, Z. Laghfour, A. Maaroufi, M. Abd-Lefdil, D. Chaumont and Z. Sekkat, Mater Lett, 2015, 139, 26-30.

61. C. M. Mbulanga, Z. N. Urgessa, S. R. T. Djiokap, J. R. Botha, M. M. Duvenhage and H. C. Swart, Physica B, 2016, 480, 42-47.

62. S. Srivastava, A. K. Srivastava, P. Singh, V. Baranwal, R. Kripal, J. H. Lee and A. C. Pandey, J Alloy Compd, 2015, 644, 597-601.

63. S. K. Maji, A. K. Dutta, P. Biswas, B. Karmakar, A. Mondal and B. Adhikary, Sensor Actuat B-Chem, 2012, 166, 726-732.

64. M. K. Debanath and S. Karmakar, Mater Lett, 2013, 111, 116-119.

65. J. Tang, J. W. Chai, J. Huang, L. Y. Deng, X. S. Nguyen, L. F. Sun, T. Venkatesan, Z. X. Shen, C. B. Tay and S. J. Chua, Acs Appl Mater Inter, 2015, 7, 4737-4743.

66. Y. S. Liu and W. Gao, J Alloy Compd, 2015, 629, 84-91.

67. S. S. Kurbanov, H. C. Jeon, Z. S. Shaymardanov, R. Y. Rakhimov and T. W. Kang, J Lumin, 2016, 170, 168-173.

68. D. Scarpellini, S. Paoloni, P. G. Medaglia, R. Pizzoferrato, A. Orsini and C. Falconi, Mater Res Bull, 2015, 65, 231-237.

69. D. M. Hofmann, D. Pfisterer, J. Sann, B. K. Meyer, R. Tena-Zaera, V. Munoz-Sanjose, T. Frank and G. Pensl, Applied Physics A, 2007, 88, 147-151.

70. H. Zeng, G. Duan, Y. Li, S. Yang, X. Xu and W. Cai, Advanced Functional Materials, 2010, 20, 561572.

71. Y. Da and Y. Xuan, Optics express, 2013, 21, A1065-A1077. 